\title{
Modeling the inhalation enhancement factor in prospective radiological risk assessment
}

\author{
M.A. Wasiolek \\ Sandia National Laboratories, 1180 N. Town Center \\ Dr. Las Vegas, NV 89144, USA
}

\begin{abstract}
Inhalation of suspended particulates originating from contaminated soil is an important exposure pathway that may result from disposal of long-lived solid radioactive waste. A hypothetical scenario was evaluated involving long-term irrigation of agricultural land with contaminated water and ensuing accumulation of radionuclides in surface soil. One of the factors affecting the dose from inhalation of suspended soil particulates is the radionuclide enhancement (enrichment) in airborne soil particles relative to that of the underlying soil. The enhancement factor (enrichment factor) is defined as a ratio of airborne particle activity concentration $\left(\mathrm{Bq} \mathrm{kg}^{-1}\right)$ to surface soil activity concentration $\left(\mathrm{Bq} \mathrm{kg}^{-1}\right)$. The values of this parameter and its effect on inhalation dose were evaluated for different soil types and inhalation exposure conditions.
\end{abstract}

\section{INTRODUCTION}

Inhalation of suspended particulates originating from contaminated soil is an important exposure pathway that may result from disposal of long-lived solid radioactive waste. In radiological assessments, it is often assumed that inhaled particulates originating from contaminated soil have the same radionuclide concentration as the bulk soil. One of the factors that can affect the dose from inhalation of suspended soil particulates is the radionuclide enhancement (enrichment) in airborne soil particles relative to that of the underlying soil, which results from the particle size-dependent distribution of contaminants among soil grains and the particle size-dependent distribution of atmospheric aerosols of soil origin. The enhancement factor (enrichment factor) is defined as a ratio of airborne particle activity concentration $\left(\mathrm{Bq} \mathrm{kg}^{-1}\right)$ to surface soil activity concentration $\left(\mathrm{Bq} \mathrm{kg}^{-1}\right)$.

The overall availability for resuspension of soil particles depends on many variables, including the characteristics of the disturbing force (e.g., wind or mechanical disturbance) and soil characteristics, such as grain size and mineralogy. Ambient aerosols are typically naturally separated into fine particle modes and a coarse particle mode. These distributions overlap between 1 and $3 \mu \mathrm{m}$ aerodynamic diameter. Resuspended soil is found primarily in the coarse fraction of resuspended particulate matter, which is formed by mechanical disruption of natural and human origin. Fine particle modes are formed by other processes, such as combustion and chemical reactions in the atmosphere. Resuspension is a particle size-selective process, and therefore the size distribution of resuspended soil particles reflects the size distribution of the soil as well as the characteristics of the resuspension process.

Contaminant interaction with soil involves processes, such as surface adsorption, which favor small, clay-size particles, because of their high surface-to-mass ratio. Therefore, small particles will carry the bulk of adsorbed contaminants, especially for the highly sorbing elements, such as $\mathrm{Pu}$, Th and $\mathrm{U}$ [1-3]. For these elements, consideration of environmental transport and human exposure pathways may need to include the particle size-dependent processes. The present work evaluated some aspects of particle size-selective processes involved in resuspension and subsequent inhalation of resuspended soil.

\section{METHODS}

The particle size-dependent enhancement arises because the concentration of the contaminant sorbed onto the soil grains is proportional to the surface area available for sorption. Small particles have a 
larger surface-to-volume ratio than large particles and thus have a greater potential for contaminant adsorption per unit mass. Using a simple geometric approach, the enhancement factor for radionuclides adsorbed to surfaces of soil grains can be expressed as a ratio of the available surface area per unit mass of suspended particulates to the available surface area per unit mass of underlying soil. Assuming that the ratio of the particle surface area to its mass (volume) is proportional to the inverse of the particle size, and that this relationship is appropriate for the soil and for suspended particulates, it is possible to calculate the surface-to-mass ratios for particles characterized by such distributions as well as the resulting enhancement factor. The assumptions stated above reduce the process of particle sizedependent enrichment to a first-order approximation based on simple, geometric considerations. Such an approach ignores many other factors that control the distribution of a contaminant between the particle sizes. However, because it captures an important relationship between the size of soil particles and their sorptive properties, it can provide insight into the importance of several parameters that influence the level of airborne contaminants originating from contaminated soil. The surface-to-mass ratios for the resuspended soil particles were calculated using the single-mode and bimodal distributions of suspended soil particles (represented by lognormal distributions) and the analytical expression describing the particle size distribution of the soils [4].

\section{RESULTS AND DISCUSSION}

For the environments with low aerosol concentrations in air (on the order of a few tens to a few hundreds of $\mu \mathrm{g} \mathrm{m}^{-3}$ ), the measured particle size distributions of resuspended soil can be approximated by a singlemode, lognormal distribution with a mass median aerodynamic diameter (MMAD) in the range from 2 to $6 \mu \mathrm{m}$ and a geometric standard deviation (GSD) of about 2 [5-8]. Using the method described above, the enhancement factor for resuspended soil particles was calculated for the three example soil types that can be characterized as sandy soil, loam soil and clay soil and for the distributions of resuspended particulates with a MMAD of $2 \mu \mathrm{m}, 4 \mu \mathrm{m}$ and $6 \mu \mathrm{m}$, and a GSD of 2 . The characteristics of the particle size distributions, along with the calculated enhancement factors, are presented in Table 1. It has been observed that the single mode of the coarse aerosol fraction distribution is generally not related to the size distribution of the soil over which measurements were taken [6]. Therefore, the enhancement factor was calculated for all the soil type-particle size distribution combinations listed in Table 1.

Table 1. Characteristics of Single-Mode Particle Size Distributions of Resuspended Soil for Low Atmospheric Aerosol Loading Conditions and Estimated Enhancement Factors.

\begin{tabular}{|c|c|c|c|c|}
\hline MMAD & & \multicolumn{3}{|c|}{ Enhancement factor } \\
\cline { 3 - 5 }$(\mu \mathrm{m})$ & GSD & Sandy soil & Loam soil & Clay soil \\
\hline 6 & 2 & 3.7 & 1.4 & 0.7 \\
\hline 4 & 2 & 5.5 & 2.1 & 1.0 \\
\hline 2 & 2 & 11.0 & 4.2 & 2.0 \\
\hline
\end{tabular}

As expected, the enhancement is largest for the sandy soils and for the low MMADs of the airborne particulates, i.e., the enhancement factor increases as the distribution of the airborne aerosols becomes more biased towards small particles, relative to the particle size distribution of the bulk soil. This is a consequence of the fact that clay-size particles tend to concentrate strongly sorbing contaminants. If these particles are then selectively resuspended and/or the clay-size particles contribute only a small fraction of the soil mass (while carrying the bulk of activity), as in sandy soils, the resulting enhancement factor can be significant.

For the conditions of heavy atmospheric aerosol loading, e.g., during mechanical soil disturbances or very strong winds, the particle size distribution tends to be bimodal, with a large particle component [5, 9-11]. This component is transient and residence times in air of large particulates, suspended as a result of mechanical soil disturbance, are only on the order of seconds due to gravitational settling [5]. 
While freshly generated coarse mode aerosol may have a MMAD of up to about $90 \mu \mathrm{m}$ [11], with time the large particles will rapidly settle out, leaving a distribution enriched with smaller-size particles [9].

The particle size distributions for very heavy aerosol loading, freshly generated by heavy military equipment on unpaved roads, were measured on sandy and silty soils, and, in both cases, the distributions of resuspended soil were bimodal [11]. During these experiments, the atmospheric mass loading was extremely high, up to $1.6 \mathrm{~g} \mathrm{~m}^{-3}$ for the sandy soils and over $2 \mathrm{~g} \mathrm{~m}^{-3}$ for silty soil. In another set of experiments, involving high aerosol loading generated by blowing dust $[6,11]$, the distributions were also bimodal. The results of these experiments were used in the calculations of the enhancement factor. The parameters describing the bimodal particle size distributions and the experimental conditions, along with the calculated enhancement factors, are summarized in Table 2.

Table 2. Characteristics of Bimodal Particle Size Distributions of Resuspended Soil for High Atmospheric Aerosol Loading Conditions and Estimated Enhancement Factors.

\begin{tabular}{|c|c|c|c|c|c|c|c|c|c|}
\hline & \multicolumn{3}{|c|}{$\begin{array}{c}\text { Small Particle Mode } \\
\text { of Coarse Aerosol Fraction }\end{array}$} & \multicolumn{4}{c|}{$\begin{array}{c}\text { Large Particle Mode } \\
\text { of Coarse Aerosol Fraction }\end{array}$} & \\
\cline { 2 - 10 } & $\begin{array}{c}\text { MMAD } \\
(\mu \mathrm{m})\end{array}$ & GSD & $\begin{array}{c}\text { Mass } \\
\text { loading } \\
\left(\mathrm{g} \mathrm{m}^{-3}\right)\end{array}$ & $\begin{array}{c}\text { Fraction } \\
\text { of mass } \\
\text { in mode }\end{array}$ & $\begin{array}{c}\text { MMAD } \\
(\mu \mathrm{m})\end{array}$ & GSD & $\begin{array}{c}\text { Mass } \\
\text { loading } \\
\left(\mathrm{g} \mathrm{m}^{-3}\right)\end{array}$ & $\begin{array}{c}\text { Fraction } \\
\text { of mass } \\
\text { in mode }\end{array}$ & EF \\
\hline 1 & 9.5 & 2.1 & 0.18 & 0.22 & 95.0 & 1.6 & 0.62 & 0.78 & 0.7 \\
\hline 2 & 19.4 & 2.0 & 1.63 & 0.78 & 72.4 & 1.6 & 0.45 & 0.22 & 0.4 \\
\hline 3 & 9.6 & 2.1 & 0.019 & 0.07 & 94.2 & 1.7 & 0.25 & 0.93 & 0.4 \\
\hline 4 & 6.2 & 2.2 & 0.025 & 0.53 & 70.0 & 1.4 & 0.02 & 0.47 & 0.8 \\
\hline
\end{tabular}

$\mathrm{EF}=$ Enhancement factor

Numbers in the first column correspond to the following experimental conditions:

1 - Sandy soil, fresh dust generated by heavy military equipment [11]

2 - Silty soil, fresh dust generated by heavy military equipment [11]

3 - Sandy soil, blowing dust [11]

4 - Loamy soil, blowing dust $[6,11]$; measurements taken in rural area of west Texas. Based on the prevalent soil types in that region it is assumed here that the soils were loamy.

For the experiments summarized in Table 2, the calculated enhancement factor was less than 1, which would indicate lower contaminant concentration of resuspended soil compared to that of bulk soil and thus depletion of resuspended soil in small, clay-size particles compared to that of bulk soil. However, this effect is likely artificial, because the enhancement factor calculation does not take into account soil aggregates, and that small clay particles may adhere to larger, resuspended particles. More likely, for the conditions of high and very high dust loading, the concentration of contaminants sorbed onto particles of resuspended soil is comparable to that of bulk soil.

Deposition of radioactive aerosols in the respiratory tract is particle size-dependent and, consequently, so is inhalation dose. As discussed above, environmental aerosols consisting of resuspended soil particles are polydisperse. Ideally, inhalation dose would be calculated by using the actual particle size-dependent distribution of radionuclide concentration in air (i.e., corrected for the concentration enhancement, if necessary), coupled with the particle size-dependent distribution of inhalation dose coefficients. In practice, numerous biases may be present, such as the particle sizedependent sampling of ambient aerosols [12]. As a result, the measured and true distributions of aerosol concentrations, as well as the activity concentrations in air, may differ. In some assessments, the distribution of airborne radioactive aerosols may be unknown. Furthermore, dose coefficients used in radiological assessments are not typically expressed as particle size-dependent functions, but rather as single values for an assumed distribution of activity over particle sizes.

A study was conducted to evaluate the impact on the inhalation exposure of the uncertainty associated with the particle size distribution of the ambient aerosols [12]. The authors concluded that to minimize the impact of an unknown particle size distribution on estimates of inhalation exposure, 
an inhalable sampler should be chosen, i.e., a sampler that collects particles with the size spectrum corresponding to that of particles that a person can inhale. They also recommend that, in the absence of precise information on the particle size characteristics of the ambient aerosols, the default values for the distribution should be the activity median aerodynamic diameter (AMAD) of $5 \mu \mathrm{m}$ and a GSD of 2.5. The findings concerning the distribution of suspended activity and the enhancement factor presented in this paper are consistent with these recommendations.

\section{CONCLUSIONS}

In summary, when the radionuclide concentration in air is calculated for the scenarios involving soluble contaminant in the soil and the subsequent resuspension of contaminated soil, the enhancement of radionuclide concentration in the airborne soil-derived aerosols, compared to that of bulk soil, may need to be taken into account. The enhancement factor is strongly dependent on the characteristics of the soil and on the presence of soil-disturbing activities. The values of the enhancement factor, calculated using a simple geometric approach, indicate that the radionuclide concentration of the airborne aerosols is likely to be significantly greater than that for the underlying soil only for the sandy soils under conditions of low (typical) atmospheric mass loading and, to a lesser degree, for the silty soils. High atmospheric aerosol loadings do not result in the enhancement of resuspended activity concentration, but such conditions are transient and not typical for most inhalation exposure circumstances. Because the enhancement depends strongly on the characteristics of the soil and the atmospheric mass loading, the site-specific conditions should be considered in radiological assessments, especially when the conditions are known to be favorable for this effect to occur.

\section{Acknowledgments}

This manuscript has been authored by Sandia National Laboratories under Contract DE-AC04-94AL85000 with the U.S. Department of Energy. The publisher, by accepting the article for publication, acknowledges that the United States Government retains a non-exclusive, paid-up, irrevocable, world-wide license to publish or reproduce the published form of this manuscript, or allow others to do so, for United States Government purposes. The statements expressed in this article are those of the author and do not necessarily reflect the views or policies of the U.S. Department of Energy or Sandia National Laboratories.

\section{References}

[1] Sheppard S.C. and Evenden W.G. Environ. Geochem. Health 14 (1992) 121-131.

[2] Sheppard S.C. and Evenden W.G. J. Environ. Qual. 23 (1994) 604-613.

[3] U.S. Environmental Protection Agency. Understanding Variation in Partition Coefficient, Kd, Values (U.S. Environmental Protection Agency, Washington, D.C., 1999).

[4] Skaggs T.H., Arya L.M., Shouse P.J. and Mohanty B.P. Soil Sci. Soc. Am. J. 65 (2001) 1038-1044.

[5] National Council on Radiation Protection and Measurements. Recommended Screening Limits for Contaminated Surface Soil and Review of Factors Relevant to Site-Specific Studies, NCRP Report No. 129 (National Council on Radiation Protection and Measurements, Bethesda, Maryland, 1999).

[6] Patterson E.M. and Gillette D.A. J. Geophys. Res. 82 (1977) 2074-2082.

[7] Dorrian M.-D. Radiat. Prot. Dosimet. 69 (1997) 117-132.

[8] Pinnick R.G., Fernandez G., Martinez-Andazola E., Hinds B.D., Hansen A.D.A. and Fuller K. J. Geophys. Res. 98 (1993), 2651-2666.

[9] U.S. Environmental Protection Agency. Air Quality Criteria for Particulate Matter (U.S. Environmental Protection Agency, Washington, D.C., 1996).

[10] Johnston P.N., Lokan K.H. and Williams G.A. Health Phys. 63 (1992) 631-640. 
[11] Pinnick R.G., Fernandez G., Hinds B.D., Bruce C.W., Schaefer R.W. and Pendleton J.D. Aerosol Sci. Tech. 4 (1985) 99-121.

[12] Degrange J.-P. and Witschger O. "Aerosol Sampling for Radiological Protection: Which Particle Size Aerosol Sampler to Select?" Naturally Occurring Radioactive Materials (NORM IV), Proceedings of an International Conference held in Szczyrk, Poland, 17-21 May 2004. (International Atomic Energy Agency, Vienna, Austria 2005) pp. 389-407. 
